\title{
Utilization of RS-3 Rice Starch into Development of Food for Elderly: A Ready-to-mix Beverage Case
}

\author{
Atittaya Tandhanskul ${ }^{1, *}$, Patchanee Yasurin ${ }^{2}$, Praewpan Chavanon ${ }^{2}$, Pattarawadee Watanakijcharoenman ${ }^{2}$, Malinee \\ Sriariyanun $^{3}$, Supawan Rattanakom ${ }^{4}$, and $I r$. Lindayani ${ }^{5}$ \\ ${ }^{1}$ Department of Food Technology, Theophane Venard School of Biotechnology, Assumption University, Bangkok, 10240, Thailand \\ ${ }^{2}$ Department of Food Biotechnology, Theophane Venard School of Biotechnology, Assumption University, Bangkok, 10240, Thailand \\ ${ }^{3}$ Department of Chemical and Process Engineering, The Sirindhorn International Thai-German Graduate School of Engineering \\ (TGGS), King Mongkut's University of Technology North Bangkok, Bangkok, 10800, Thailand \\ ${ }^{4}$ Department of Mathematics, Martin de Tours School of Management and Economics, Assumption University, Bangkok, 10240, \\ Thailand \\ ${ }^{5}$ Food Technology Program, Soegijapranata Catholic University (SCU), Semarang, Indonesia
}

\begin{abstract}
As population aging is becoming a global phenomenon, the search for food for elderly continues. Since elderly population is associated with non-communicable diseases, elderly food development must provide nutritious value and physiological needs. The objective of this study was to develop a ready-to-mix beverage with resistant rice starch type 3 (RS-3) as one of the ingredients. Five Thai rice varieties were modified into resistant-starch type 3 (RS-3). The dietary quality was conducted by measuring rapidly available glucose (RAG) and slowly available glucose (SAG) which was used for primary study of the glycemic index (GI). Riceberry variety showed the highest potential and was used to formulate. Market survey with elderly population $(n=400$, age $>50)$ revealed additional protein and vegetables that should be included in the beverage. Mixture design was used to initiate the formulation before fine-tuning with sensory analysis. Sucralose was utilized as an alternative sweetener and xanthan gum was added to improve the texture and viscosity to assist population with dysphagia. Using a 7-point hedonic face scale, panelists liked the product slightly to moderately with $0.7 \%$ xanthan gum $(5.7 \pm 1.09)$ and $0.1 \%$ sucralose $(5.5 \pm 0.89)$. The viscosity of water and beverage $\operatorname{mix}$ at $150: 12(\mathrm{w} / \mathrm{w})$ were found appropriate for patient with dysphagia $(700 \pm 12.50 \mathrm{mPa} . \mathrm{s})$. The appropriate formulation of RS3-rice starch into elderly beverage were developed, however, the consumer acceptance test is suggested to be continued.
\end{abstract}

Keyword. Elderly beverage; RS-3 rice starch; elderly food development; dysphagia beverage; beverage for diabetes

\section{Introduction}

Aging population is on the rise globally. This requires the continuous development of a healthy meal for elderly that should reduce the burden of chronic diseases and avoid loss of function and disability. The role of nutrients, foods, and diet patterns became the subject of study for identifying the best food intake recommendations to achieve a better health and wellbeing [1]. With the decline in digestive, olfactory, and salivary functions, as well as in hormonal profile affect the nutritional status of elderly population. The design for a better meal replacement is a challenge as elderly population is often associated with the presence of chronic diseases, multiple medications, cognitive impairment, and depression. [2] In Thailand, an elderly population is expected to meet $25 \%$ of total Thai population, or approximately 17.5 million people in 2028 [3].

Consumption of well-balanced meals is a key to maintaining a healthy lifestyle. Carbohydrates are required for elderly nutrition as they provide human body a primary source of fuel for body and brain functioning. Rice is one of the global staples and a good option for developing elderly food. It is easy to cook, digest, and comparatively less expensive than other food items offering similar nutritional value. Rice is cholesterol free, low in sodium and helps in managing blood pressure [4]. However, ingesting rice can become problematic in elderly since rice can be digested too quickly which increases body blood sugar level and raises risk of diabetes.

To solve this challenge, starch is modified into resistant starch, fractions that are indigestible by body enzymes [5]. Although there are 4 types of resistant starch, resistant starch type 3 (RS3) is starch which is made resistant to hydrolysis by exhaustive $\alpha$-amylase and pullulanase treatment in vitro [6]. The benefits of resistant starch involve in the prevention and control of chronic human diseases, including diabetes, colon cancer, and obesity [7]. Designing an elderly food should concern the prevention of insufficient nutritional status. Selection of ingredients to be added into the prototype is subsequently performed based on consumer need. 
Since swallowing difficulty, known as dysphagia, and diabetes mellitus are commonly found in the elderly, there is still a need for development of a texturemodified foods suitable for blood sugar control. This study aims to use RS-3 rice starch as an ingredient to help control blood sugar level and modify the beverage texture to suit those suffered from dysphagia.

\section{Materials and Method}

Initially, 5 Thai rice varieties were selected and purchased from local supermarket (red, riceberry, black glutinous, Sao Hai, and brown). Each rice variety was modified enzymatically and physically as described by [8-9]. Vegetables used in the formula were decided from the results of the survey (carrot, corn, and pumpkin) and processed into dry powder form. Pea protein isolate was used as a protein source.

\subsection{Determination of Rapidly available Glucose (RAG) and Slowly Available Glucose (SAG)}

Five $\mathrm{ml}$ pepsin was added into 0.1 grams sample. Sample was heated at $37^{\circ} \mathrm{C}$ in water bath for 30 minutes. After that, $10 \mathrm{ml}$ of $0.1 \mathrm{M}$ sodium acetate was added into sample. Five glass beads with $1.5 \mathrm{~cm}$ diameter were added into sample and followed by addition of $2.5 \mathrm{ml}$ enzyme mixtures which include pancreatin, invertase and amyloglucosidase enzymes. The sample was shaken by shaker with the control temperature at $37^{\circ} \mathrm{C}$ for 20 minutes and the sample was collected (G20). The shaking continued for another 100 minutes before the sample was collected (G120). Amount of glucose was determined by using blood glucose monitoring system (ACCU-chek instant S blood glucose meter) [10-11].

\subsection{Market Survey of Elderly Need towards a new developed product}

A survey was conducted with 400 elderly people in Bangkok Metropolitan region by the participants whose age were more than 50 years old. A questionnaire was used to screen the consumer need in order to formulate and develop the product. In the questionnaire, there were 4 parts including (1) the consumer behavior, (2) the factors that influence of purchasing rice beverage, (3) the consumer opinion on rice beverage ingredients and (4) demographic data.

\subsection{Designing a prototype}

\subsubsection{Texture adjustment}

Resistance starch type 3 (RS3) rice powder was mixed with carrot powder, corn powder, pumpkin powder and pea protein isolate. Xanthan gum was added at $0 \%$ as a control, $0.3 \%, 0.5 \%, 0.7 \%$ and $0.9 \%$ to study the effect of texture modification. The hot water $(150 \mathrm{ml})$ was added into samples and stirred until mixed before serving.

\subsubsection{Sweetness adjustment}

Resistance starch type 3 (RS3) rice powder was mixed with carrot powder, corn powder, pumpkin powder and pea protein isolate. Sucralose was added at $0 \%$ as a control, $0.1 \%, 0.2 \%$ and $0.3 \%$ to study the effect of sweetness modification. The hot water $(150 \mathrm{ml})$ was added into samples and stirred until mixed before serving.

\subsubsection{Viscosity measurement}

The formulas as described in 2.3.1 were additionally determined for their viscosity. The NDJ-1 Rotational Viscometer at rotor no.2 at $12 \mathrm{rpm}$ was used to measure viscosity.

\subsubsection{Sensory evaluation}

Sensory analysis of formulas at different concentration of xanthan gum and sucralose were evaluated. The 30 panelists, whose age were over 50 years old, were included for sensory testing. The sensory form template was designed to use a 7-point hedonic face scale which measured the sensory properties of appearance, color, rice flavor, vegetable flavor, saltiness, sweetness, viscosity and overall acceptability to find the best formula of the RS3-rice beverage (Fig. 1). Three-digit random numbers were used to code the samples and the serving order was counterbalanced.

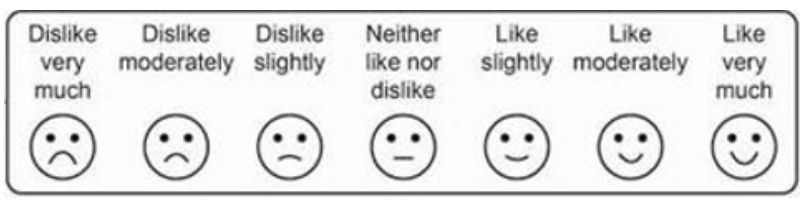

Fig. 1. The 7-point hedonic face scale.

\subsection{Statistical Analysis}

The data collected from was statistically analyzed using SAS software (version 9.4). The results were reported as mean \pm standard deviations. One-way ANOVA for Randomized Complete Block Design (RCBD) was used to analyze the result and Duncan Multiple Range Test was further analyzed when the significantly difference was detected. Significance of difference were defined as $\mathrm{p}<0.05$.

\section{Results and Discussion}

\subsection{Determination of Rapidly available Glucose (RAG) and Slowly Available Glucose (SAG)}

Selection of Thai rice varieties for developing a prototype for RS-3 rice beverage was performed by determination of RAG and SAG of the rice samples. All rice varieties exhibited lower in level of glucose detected. Modified riceberry starch showed the lowest RAG or the glucose level measured after 20-min 
digestion (26.13 \pm 0.53$)$ and a slightly higher level of glucose after 120 -min digestion $(27.71 \pm 0.61)$. This result indicated that riceberry was slowly digested to release the glucose into the system (Table 1). Riceberry is also known as a medium GI rice variety that has been used to develop riceberry rice pudding for people with dysphagia and those need to control blood sugar level [12].

Table 1. RAG and SAG of native rice starches and modified rice starches.

\begin{tabular}{|c|c|c|c|c|}
\hline \multirow{2}{*}{$\begin{array}{c}\text { Varieties } \\
\text { of rice }\end{array}$} & \multicolumn{2}{|c|}{ RAG (g/100g sample) } & \multicolumn{2}{c|}{ SAG (g/100g sample) } \\
\cline { 2 - 5 } & Native & Modified & Native & Modified \\
\hline Red rice & $40.89 \pm 0.56^{\mathrm{b}}$ & $31.09 \pm 0.62^{\mathrm{b}}$ & $38.44 \pm 0.35^{\mathrm{b}}$ & $26.95 \pm 0.53^{\mathrm{a}}$ \\
\hline Riceberry & $38.85 \pm 0.46^{\mathrm{c}}$ & $26.13 \pm 0.53^{\mathrm{c}}$ & $38.68 \pm 0.53^{\mathrm{b}}$ & $27.71 \pm 0.61^{\mathrm{a}}$ \\
\hline $\begin{array}{c}\text { Black } \\
\text { glutinous }\end{array}$ & $47.78 \pm 0.46^{\mathrm{a}}$ & $40.66 \pm 0.53^{\mathrm{a}}$ & $52.04 \pm 0.62^{\mathrm{a}}$ & $19.83 \pm 0.53^{\mathrm{b}}$ \\
\hline $\begin{array}{c}\text { Sao Hai } \\
\text { rice }\end{array}$ & $48.28 \pm 0.59^{\mathrm{a}}$ & $41.26 \pm 0.62^{\mathrm{a}}$ & $55.11 \pm 0.48^{\mathrm{a}}$ & $22.79 \pm 0.27^{\mathrm{b}}$ \\
\hline $\begin{array}{c}\text { Brown } \\
\text { rice }\end{array}$ & $41.15 \pm 0.64^{\mathrm{b}}$ & $33.97 \pm 0.47^{\mathrm{b}}$ & $38.05 \pm 0.38^{\mathrm{b}}$ & $27.94 \pm 0.71^{\mathrm{a}}$ \\
\hline
\end{tabular}

\subsection{Market Survey of Elderly Need towards a new developed product}

After a survey with 400 elderly participants, those who aged more than 50 years old, using questionnaire, the consumer behaviors, factors affecting buying decision, and consumer's opinion towards a beverage product were analyzed.

\subsubsection{Consumer behaviors}

From Table 2, most consumers had meals 3 meal per day $(58.8 \%)$ and decided to buy food by themselves $(67.25 \%)$ which the food cost per meal was in the range of $50 \mathrm{THB}$ to $100 \mathrm{THB}$, or USD 2-4 (data not shown). Moreover, food with fortified vitamins and minerals interested the elderly the most (16.2\%). The survey revealed that the cost of buying the healthy food in 1 month for elderly was in the range of 501 THB to 1,500 THB, or USD 15-50. Most of the participant population bought food from the supermarket every week and they have never bought food online. In addition, elderly participants preferred to eat or drink food that contained no preservative in product (data not shown).

\subsubsection{Factors influencing buying decision}

The important factors for the selection of purchasing ready-to-drink rice beverage or soup from consumer survey (1 refers to "least important" and 5 refers to "most important") were investigated (Table 3). According to the survey, 'safety' of the product was rated as the highest factor is fairly important to the elderly (4.34 \pm 0.87$)$ while 'nutrition' and 'freshness' factors were in the range of "fairly important" but scores were lower, 4.23 and 4.09, respectively. For 'source of raw material', 'taste', 'price', 'net volume', 'packaging', 'brand' and 'promotion' provided score in the range of "important". On the other hand, the "popularity' of the product was the only slightly important factor, 2.96, that the elderly people focused.

Table 2. Elderly consumer behaviors.

\begin{tabular}{|l|l|}
\hline \multicolumn{1}{|c|}{ Criteria } & Percentage \\
\hline Number of meal per day & 58.8 \\
\hline 3 meals & 35.5 \\
\hline 2 meals & 1.0 \\
\hline 1 meal & 5.0 \\
\hline Other & 67.25 \\
\hline Decision Making & 20.0 \\
\hline Self & 12.75 \\
\hline Self-decision but other buys & \\
\hline Other & 16.2 \\
\hline Characteristics elderly interested \\
\hline Vitamin fortified & 15.9 \\
\hline Nourishing & 12.3 \\
\hline Weight control & 12.2 \\
\hline Disease prevention & 9.7 \\
\hline Create fullness & 9.4 \\
\hline Snack & 9.0 \\
\hline Meal substitute & 8.4 \\
\hline Rice substitute & 3.8 \\
\hline Dinner substitute & 0.1 \\
\hline Other & \\
\hline & \\
\hline &
\end{tabular}

Table 3. Factors affecting buying decision.

\begin{tabular}{|l|c|}
\hline \multicolumn{1}{|c|}{ Factors } & Importance score \\
\hline Safety & $4.34 \pm 0.87$ \\
\hline Nutrition & $4.23 \pm 0.86$ \\
\hline Freshness & $4.09 \pm 0.92$ \\
\hline Source of raw material & $3.90 \pm 0.91$ \\
\hline Taste & $3.80 \pm 0.98$ \\
\hline Price & $3.58 \pm 1.05$ \\
\hline Net volume & $3.31 \pm 0.97$ \\
\hline Packaging & $3.28 \pm 1.06$ \\
\hline Brand & $3.16 \pm 0.89$ \\
\hline Promotion & $3.11 \pm 1.19$ \\
\hline Popularity & $2.96 \pm 0.95$ \\
\hline
\end{tabular}

\subsubsection{Consumer opinions}

According to Table 4, it can be described that the elderly participants preferred the characteristic of the ready-todrink rice beverage in form of beverage powder. The type of vegetables which most of elderly choose to add in product including carrot $(11.78 \%)$, corn $(10.77 \%)$ and pumpkin $(10.20 \%)$, respectively (data not shown). The 
characteristic of vegetables added was to be in form of blended with the beverage for smooth texture $(27.79 \%)$, followed by adding as small pieces $(23.35 \%)$. From figure 2 , the elderly population who were interested in a new product made from modified rice and a variety of vegetables, processed to have a low GI, suitable for the elderly and people who want to control their blood sugar levels was $74 \%$.

Table 4. Factors affecting buying decision.

\begin{tabular}{|c|c|}
\hline Criteria & Percentage \\
\hline \multicolumn{2}{|l|}{ Characteristic of beverage } \\
\hline Beverage powder & 23.96 \\
\hline Ready-to-drink & 19.82 \\
\hline Ready-to-eat soup & 18.43 \\
\hline Soup powder & 14.86 \\
\hline Smooth texture & 14.75 \\
\hline Contain meat for chewing & 8.18 \\
\hline \multicolumn{2}{|c|}{ Characteristic of vegetables added } \\
\hline Blended with beverage & 27.79 \\
\hline Small piece & 23.35 \\
\hline Small dice for chewing & 21.95 \\
\hline Dehydrated & 19.74 \\
\hline Original size & 7.27 \\
\hline
\end{tabular}

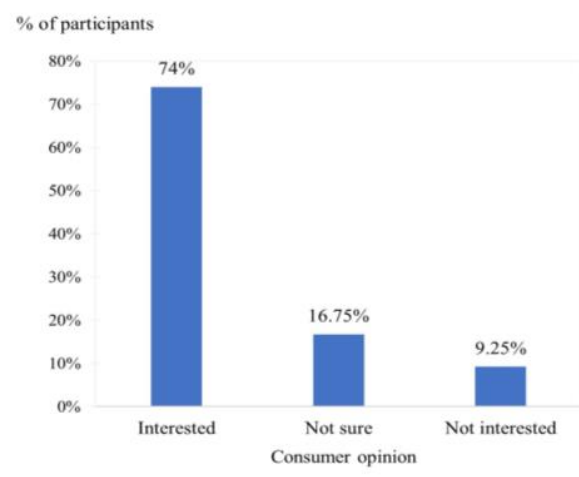

Fig. 2. The percentage of elderly participants that were interested in purchasing the new product.

\subsection{Designing a prototype}

\subsubsection{Texture adjustment}

The sensory test was done using 7-point hedonic face scale. The liking scores of sensory acceptability of formulas with five different concentration xanthan gum in attributes including appearance, color, rice flavor, vegetable flavor, saltiness, sweetness, viscosity and overall liking of the samples were shown in Table 5 . There was no significant difference $(\mathrm{p} \leq 0.05)$ in color, rice flavor, vegetable flavor and saltiness when compared to the control ( $0 \%$ of xanthan gum). However, the result of $0.7 \%$ of xanthan gum showed the significant difference in sweetness, viscosity and overall liking (4.4 $\pm 1.42,5.2 \pm 1.28$ and $5.7 \pm 1.09$, respectively). The $0.7 \%$ of xanthan gum was selected to develop the further formula due to the overall liking score was highest.

According to the previous study [13], the flavor and appearance influenced to the liking of the food samples based on a 3-point hedonic scale in texture-modified foods (TMFs). Table 5 showed that the appearance affected to the overall liking which corresponded to the research of Okkels et al. [13].

\subsubsection{Sweetness adjustment}

Barragán et al. [14] reported the preference of sweet foods was consistent although increase in age affected perceived taste sensitivity including salty, sour and bitter tastes were influenced. However, a study by Wiriyawattana et al. [15] showed that the detection and recognition in sweet taste in elderly needed higher sucralose concentration than the younger ones. According to Schiffman [16], the decline in taste sensitivity with aging related to the sweetener molecules by large sweetener molecules had more possible sites for hydrogen bonding with the receptors than small sweetener molecules which the molecular weight of sucralose was $397.64 \mathrm{~g} / \mathrm{mol}$.

In this study, the effect of difference concentration of sucralose found no significant difference $(\mathrm{p} \leq 0.05)$ in appearance, color, rice flavor, vegetable flavor and saltiness of the samples (Table 6). However, the result of $0.1 \%$ of sucralose showed the significant difference in sweetness $(4.6 \pm 1.43)$ and overall liking $(5.5 \pm 0.89)$ when compared to the control ( $0 \%$ of sucralose).

Table 5. Sensory evaluation of different amount of xanthan gum used in development of RS3-rice beverage.

\begin{tabular}{|c|c|c|c|c|c|}
\hline \multirow{2}{*}{ Attributes } & \multicolumn{5}{|c|}{ Amount of xanthan gum (\%) } \\
\hline & $0 \%$ & $0.3 \%$ & $0.5 \%$ & $0.7 \%$ & $0.9 \%$ \\
\hline Appearance & $4.6 \pm 1.23^{a b}$ & $4.7 \pm 1.09^{\mathrm{ab}}$ & $5.2 \pm 1.24^{\mathrm{a}}$ & $4.9 \pm 1.32^{\mathrm{ab}}$ & $4.4 \pm 1.49^{b}$ \\
\hline Color $^{\text {ns }}$ & $4.5 \pm 1.43$ & $4.5 \pm 1.10$ & $4.8 \pm 1.47$ & $5.2 \pm 1.31$ & $4.9 \pm 1.43$ \\
\hline Rice flavor ${ }^{\mathrm{ns}}$ & $4.5 \pm 1.23$ & $4.1 \pm 1.71$ & $4.8 \pm 1.39$ & $5.0 \pm 1.31$ & $4.7 \pm 1.52$ \\
\hline Vegetable flavor ${ }^{\mathrm{ns}}$ & $4.7 \pm 1.47$ & $4.8 \pm 1.03$ & $4.8 \pm 1.35$ & $4.6 \pm 0.97$ & $4.9 \pm 1.47$ \\
\hline Saltiness $^{\mathrm{ns}}$ & $4.9 \pm 1.28$ & $4.8 \pm 0.95$ & $4.9 \pm 1.17$ & $5.4 \pm 1.18$ & $4.7 \pm 1.17$ \\
\hline Sweetness & $4.5 \pm 1.47^{\mathrm{ab}}$ & $4.4 \pm 1.42^{b}$ & $5.2 \pm 0.93^{\mathrm{a}}$ & $4.4 \pm 1.42^{b}$ & $4.5 \pm 1.54^{\mathrm{ab}}$ \\
\hline Viscosity & $4.2 \pm 1.44^{\mathrm{b}}$ & $4.8 \pm 1.11^{\mathrm{ab}}$ & $5.2 \pm 1.06^{\mathrm{a}}$ & $5.2 \pm 1.28^{\mathrm{a}}$ & $3.9 \pm 1.77^{b}$ \\
\hline Overall liking & $4.2 \pm 1.35^{\mathrm{c}}$ & $4.5 \pm 1.32^{\mathrm{cb}}$ & $5.1 \pm 1.12^{\mathrm{ab}}$ & $5.7 \pm 1.09^{\mathrm{a}}$ & $3.9 \pm 1.54^{\mathrm{c}}$ \\
\hline
\end{tabular}

Note: Different letters in the same row represent significant difference $(\mathrm{p} \leq 0.05)$ 
Table 6. Sensory evaluation of different amount of sucralose used in development of RS3-rice beverage.

\begin{tabular}{|c|c|c|c|c|}
\hline \multirow{2}{*}{ Attributes } & \multicolumn{4}{|c|}{ Amount of sucralose (\%) } \\
\hline & $0 \%$ & $0.1 \%$ & $0.2 \%$ & $0.3 \%$ \\
\hline Appearance $^{\text {ns }}$ & $4.6 \pm 1.23$ & $5.4 \pm 1.27$ & $5.3 \pm 1.07$ & $4.7 \pm 1.81$ \\
\hline Color $^{\text {ns }}$ & $4.6 \pm 1.12$ & $5.4 \pm 1.38$ & $5.3 \pm 1.25$ & $4.7 \pm 1.23$ \\
\hline Rice flavor ${ }^{\text {ns }}$ & $4.0 \pm 1.92$ & $4.7 \pm 1.42$ & $4.4 \pm 1.54$ & $4.8 \pm 1.37$ \\
\hline Vegetable flavor ${ }^{\mathrm{ns}}$ & $4.6 \pm 1.15$ & $4.8 \pm 1.36$ & $5.4 \pm 1.23$ & $5.0 \pm 1.03$ \\
\hline Saltiness $^{\text {ns }}$ & $4.7 \pm 1.13$ & $4.9 \pm 1.27$ & $5.1 \pm 1.07$ & $4.9 \pm 1.35$ \\
\hline Sweetness & $3.6 \pm 1.67^{\mathrm{b}}$ & $4.6 \pm 1.43^{\mathrm{a}}$ & $5.1 \pm 1.43^{\mathrm{a}}$ & $2.4 \pm 1.14^{\mathrm{c}}$ \\
\hline Viscosity & $4.5 \pm 1.43^{\mathrm{c}}$ & $4.7 \pm 1.42^{\mathrm{cb}}$ & $5.4 \pm 0.99^{\text {ba }}$ & $5.7 \pm 0.98^{\mathrm{a}}$ \\
\hline Overall liking & $3.9 \pm 1.52^{b}$ & $5.5 \pm 0.89^{\mathrm{a}}$ & $5.3 \pm 1.13^{\mathrm{a}}$ & $3.6 \pm 1.57^{b}$ \\
\hline
\end{tabular}

Note: Different letters in the same row represent significant difference $(\mathrm{p} \leq 0.05)$

Moreover, the increase in amount of sucralose affected the overall liking. The score of overall liking related to the score of sweetness by the score was constant at the $0.1 \%$ and $0.2 \%$ of sucralose when compared with the sucralose at $0 \%$ and $0.3 \%$. These findings indicate that the elderly could detect and recognize the sweet taste of different amount of sucralose which in agreement with the result from the previous research [15] in term of the detection and recognition sucralose concentration in sweet taste in elderly. Hence, the $0.1 \%$ of sucralose was chosen to develop formulas since it received the highest overall liking score.

\subsubsection{Viscosity measurement}

Table 7. The viscosity of RS3- rice beverage with different amount of xanthan gum.

\begin{tabular}{cc}
\hline $\begin{array}{c}\text { Amount of } \\
\text { xanthan gum }(\%)\end{array}$ & $\begin{array}{c}\text { Viscosity (Mean } \pm \text { SD) } \\
(\mathrm{mPa} . \mathrm{s})\end{array}$ \\
\hline $0 \%$ & $285 \pm 8.66^{\mathrm{c}}$ \\
$0.3 \%$ & $283.33 \pm 10.41^{\mathrm{c}}$ \\
$0.5 \%$ & $301.67 \pm 18.76^{\mathrm{c}}$ \\
$0.7 \%$ & $426.67 \pm 50.64^{\mathrm{b}}$ \\
$0.9 \%$ & $733.33 \pm 87.79^{\mathrm{a}}$
\end{tabular}

Note: Different letters in the same row represent significant difference $(\mathrm{p} \leq 0.05)$

The different amounts of xanthan gum incorporated into RS-3 rice beverage were measured for their viscosity and the result was presented in the Table 7 . Compared with the $0 \%$ of xanthan gum, the result showed that the increasing amount of xanthan gum affected the viscosity. The xanthan gum was hydrocolloid and thickening agent which used to modify the viscosity [17] and improved consistency of food to ease swallowing [18]. The $0.7 \%$ of xanthan gum showed significant difference in viscosity that it was not too thin nor too thick (426.67 \pm $50.64 \mathrm{mPa} . \mathrm{s})$. The viscosity ranges for thickened liquids in the National Dysphagia Diet (NDD) stated that the viscosity of honey thick liquids was between 351 $1,750 \mathrm{cP}$ which all the results fell in the range of honey thick liquids except the $0 \%$ of xanthan gum was in the range of nectar thick liquids [19]. In addition, the result of sensory evaluation on effect of different concentration of xanthan gum (Table 5) was found that the viscosity at $0.7 \%$ of xanthan gum received $5.2 \pm 1.28$ liking score on 7-point hedonic scale. With appropriate viscosity for patient with dysphagia, $0.7 \%$ of xanthan gum was selected as the suitable concentration to incorporate in the formula.

\section{Conclusion}

The aging population is increasing inevitably around the world. Development of food for elderly should be well designed since there is a close relationship between nutritional status and health in the elderly. The utilization of RS3-rice starch incorporated with plantbased ingredients into a ready-to-mix beverage is just one of the health claimed food products for elderly which the number of this type of products is still limited in the current market. This product is designed for people coping with dysphagia and diabetic mellitus by modifying texture and usage of alternative sweetener, sucralose. Even though the results from this study provided the appropriate formulation of RS3-rice with plant-based on ingredient beverage, the consumer acceptance test for this formulation is suggested to be continued. Furthermore, random controlled test in a specific target group will be conducted in the next phase of research.

\section{References}

1. B. Roman-Viñas, L. Serra-Majem, Diet and Healthy Patterns in the Elderly, Current Nutrition Report 3 (2014):69-87

2. L.M. Donini, P. Scardella, L. Piombo, B. Neri, R. Asprino, A.R. Proietti, Malnutrition in elderly: social and economic determinants. Journal of Nutritional Health Aging, 17, 1 (2013): 9-15.

3. SCB Intelligence Center, The business of aging and opportunities in care for the elderly (2015) https://www.scbeic.com/en/detail/product/1676

4. A. Rohman, S. Helmiyati, M. Hapsari, D.L. Setyaningrum, Rice in health and nutrition, International Food Research Journal, 21, 1 (2014): $13-24$ 
5. M.G. Sajilata, R.S. Singhal, P.R. Kulkarni, Resistant starch - A review, Comprehensive Reviews in Food Science and Food Safety, 5 (2006) 1-17

6. H. Englyst, H.S. Wiggins, J.H. Cummings, Determination of the non-starch polysaccharides in plant foods by gas-liquid chromatography of constituent sugars as alditol acetates. Analyst 107 (1982): 307-318

7. D.F. Birt, T. Boylston, S. Hendrich, J.L. Jane, J. Hollis, L. Li, K. Schalinske, Resistant starch: promise for improving human health. Advances in Nutrition, 4, 6 (2013): 587-601

8. M. Miao, B. Jiang, and T. Zhang, Effect of pullulanase debranching and recrystallization on structure and digestibility of waxy maize starch. Carbohydrate Polymers, 76 (2009): 214-221

9. J. Pongjanta, A. Utaipattanaceep, O. Naivikul, and K. Piyachomkwan, Debranching enzyme concentration effected on physicochemical properties and $\alpha$-amylase hydrolysis rate of resistant starch type III from amylose rice starch. Carbohydrate Polymers. 78 (2009): 5-9

10. H. Englyst, Classification and measurement of nutritionally important starch fractions. European journal of clinical nutrition, 46, (1992): 33-50

11. A. Wasusun, Rice Variety RD43: Medium Glycemic Index Rice for Niche Market. Division of rice research and development, (2017): 309-322

12. P. Suttireung, T. Winuprasith, W. Srichamnong, W. Paemuang, T. Phonyiam, D. Trachootham, Riceberry rice puddings: rice-based low glycemic dysphagia diets. Asia Pacific Journal of Clinical Nutrition, 28, 3 (2019): 467-475
13. S.L. Okkels, M. Saxosen, S. Bügel, A. Olsen, T. W. Klausen, A. M. Beck, Acceptance of texturemodified in-between-meals among old adults with dysphagia, Clinical nutrition ESPEN, 25, (2018): $126-132$

14. R. Barragán, O. Coltell, O. Portolés, E.M. Asensio, J.V. Sorlí, C. Ortega-Azorín, D. Corella, Bitter, sweet, salty, sour and umami taste perception decreases with age: Sex-specific analysis, modulation by genetic variants and taste-preference associations in 18 to 80 year-old subjects, Nutrients, 10, 10, (2018): 1539

15. P. Wiriyawattana, S. Suwonsichon, $T$. Suwonsichon, T. 2018. Effects of aging on taste thresholds: A case of Asian people, Journal of Sensory Studies, 33, 4, (2018): e12436

16. S.S. Schiffman, 2008. The aging gustatory system, The senses: A comprehensive reference (2008): 479-498. San Diego, CA: Academic Press.

17. R. Newman, N. Vilardell, P. Clave, R. Speyer, Effect of bolus viscosity on the safety and efficacy of swallowing and the kinematics of the swallow response in patients with oropharyngeal dysphagia: White paper by the European society for swallowing disorders (ESSD), Dysphagia, 31, (2016): 232-249

18. M. Sharma, L.J.F. Duizer, Characterizing the Dynamic Textural Properties of Hydrocolloids in Pureed Foods-A Comparison Between TDS and TCATA., 8, (2019): 184

19. R. J. Leonard, C. White, S. McKenzie, P.C. Belafsky, Effects of bolus rheology on aspiration in patients with dysphagia. Journal of the Academy of Nutrition and Dietetics, 114, 4, (2014): 590-594 